\title{
RACHEL WHITEREAD E A ARTE PÚBLICA: \\ O monumento como lugar de memória
}

\section{RACHEL WHITEREAD AND PUBLIC ART:}

The monument as a place of memory

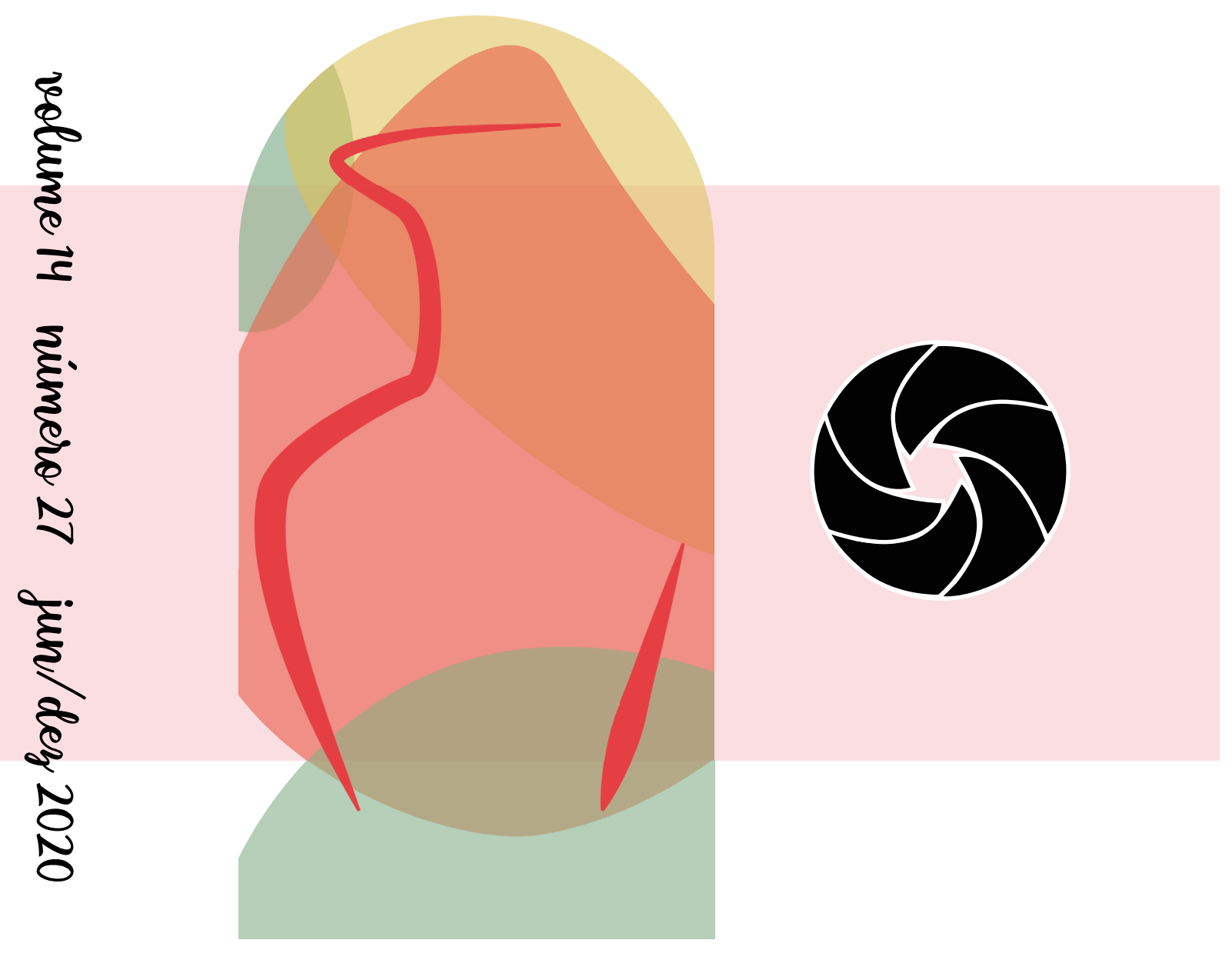

Emanuelly Mylena Velozo Silva'

manu200862@hotmail.com

Cultura Material:

objetos, imagens e representacões - 1/2 


\section{Resumo}

O monumento como categoria de obra de arte existe há séculos, tendo finalidades e graus diferentes de representação e significação. Existem alguns monumentos, principalmente os situados no espaço público, que são planejados e arquitetados exatamente de acordo com o lugar em que serão instalados, conversando in situ, diretamente com todo o redor, sendo impossível de serem realocados. Este artigo tratará de dois deles, ambos criados pela artista Rachel Whiteread, tendo como premissa para o entendimento de suas obras a teoria dos lugares de memória, de Pierre Nora. São obras que atravessam as áreas da memória, do tempo e da arte. Elas tratam também sobre como o monumento pode ser um lugar que narra diversas lembranças e passados de uma forma crítica e política.

Palavras-chave: Rachel Whiteread; Arte Pública; Monumento; Lugar de Memória.

\section{Abstract}

The monument as a category of work of art has existed for centuries, having different purposes and degrees of representation and meaning. There are some monuments, especially those located in the public space, which are planned and designed exactly with the place where they will be installed, talking in situ and directly with all around, being impossible to be relocated. This article will deal with two of them, authored by artist Rachel Whiteread, with Pierre Nora's theory of places of memory as a premise for understanding his works. These are works that cross the areas of memory, time and art. It also deals with how the monument can be a place that narrates the various memories and pasts in a critical and political way.

Keywords: Rachel Whiteread; Public Art; Monument; Place of memory.
${ }^{1}$ Graduada em Design pela Universidade Federal de Pernambuco, no Centro Acadêmico do Agreste, Caruaru$-P E$. Especialização em andamento em História da Arte pela Universidade Estácio de Sá, modalidade EAD. Mestranda no Programa de Pós-Graduação em Artes Visuais pela Universidade Federal de Pernambuco/Universidade Federal da Paraíba, Recife-PE. E-mail: manu200862@hotmail.com. 


\section{Introdução}

Na arte contemporânea, existe uma corrente que surge em um cenário artístico caracterizado pelas práticas pós-minimalistas e pela crescente produção de esculturas em espaços públicos, no final dos anos 1960: chama-se arte site-specific, e uma boa definição desse novo modelo de arte pós-moderna é feita por Richard Serra (1938-):

[...] escala, tamanho e localização dos trabalhos site-specific são determinados pela topografia do lugar, seja esse urbano ou paisagístico ou clausura arquitetônica. Os trabalhos tornam-se parte do lugar e reestruturam sua organização tanto conceitual quanto perceptivelmente". (KWON, 2009, p. 168).

Serra foi um dos grandes nomes da "arte com lugar específico", assim como Christo e Jeanne-Claude, Robert Barry, Robert Smithson, dentre outros e outras artistas. Um dos grandes expoentes dessa categoria artística foram as obras da artista contemporânea Rachel Whiteread (1963 -). Rachel nasceu em Londres e seus trabalhos são, em maioria, esculturas e instalações. Descrita por alguns críticos e curadores como artista "conceitual" e "pós-minimalista", seus trabalhos no espaço público são geralmente de proporção monumental. O que será evidenciado neste trabalho é como Rachel pensa e produz arte sobre a memória, os espaços e suas respectivas histórias e vivências. Estará em foco a análise sobre duas de suas obras presentes no espaço público: uma delas já demolida, House (1993/1994, Londres), Jüdenplatz Holocaust Memorial, inaugurada em 2000 em Viena, na Áustria. O objetivo deste artigo é analisar como essas obras de alguma maneira procuram debater crítica e ideologicamente, através da teoria dos lugares de memória, acontecimentos que tiveram efeitos na sociedade a que essas obras pertencem. São produções também descritas como site-specific, de modo que não fariam sentido em outra situação ou local.

Há muito se discute na comunidade acadêmica acerca dos lugares de memória, teoria muito reconhecida e estudada do historiador Pierre Nora (1931 -), que adotamos como ponto de partida, junto a outros conceitos e teorias sobre a memória nos estudos historiográficos. Assim, objetivamos compreender o processo artístico e as obras de Whiteread, em que se cruzam as discussões sobre o tempo, as materialidades da memória e os monumentos no espaço público.

Portanto, este artigo foi dividido em quatro partes, sendo a primeira intitulada monumentos e os lugares de memória, abordando alguns conceitos e discussões sobre o tema e sua relação com certos tipos de obras artísticas (monumentos); a segunda parte, house e a materialização do espaço, acerca da primeira obra de Rachel Whiteread em análise, que consiste em um monumento em homenagem a um conjunto de casas do final do 
século XIX, em Londres, demolidas para a construção de um parque; a terceira parte, sendo Jüdenplatz Holocaust Memorial ou The Nameless Library, segunda obra da artista analisada, um memorial em Viena em homenagem aos milhares de judeus austríacos que morreram em campos de concentração; e as considerações finais, quarta e última parte, para abordar algumas reflexões e discussões sobre o artigo.

\section{Monumentos e os lugares de memória}

Ao utilizar o termo e os estudos da memória para analisar fatos do passado, confunde-se geralmente com a própria História. Vários autores e estudiosos do tema já desmistificaram que haja uma grande diferença entre esses dois termos. Há também o uso frequente do conceito de "memória histórica", "expressão [que] não foi escolhida com muita felicidade, pois associa dois termos que se opõem em mais de um ponto" (HALBWACHS, 1990, p. 80).

Uma boa síntese da diferenciação desses dois termos é feita por Pierre Nora (1993) e Jacques Le Goff (1996). Pierre Nora explica que a memória está em permanente evolução: ela é a vida, aberta à lembrança e ao esquecimento. Já a História é a reconstrução incompleta do que não existe mais (NORA, 1993, p.9). Le Goff usará o termo de Maurice Halbwachs para explicitar que "a memória coletiva e sua forma científica, a História, aplicam-se a dois tipos de materiais: os documentos e os monumentos" (LE GOFF, 1996, p. 535). Portanto, nota-se que a memória é um meio que a História e, consequentemente, o historiador utilizam para abordar e analisar determinados assuntos e períodos. Em todo debate sobre a memória também é importante lembrar que, junto dela, haverá a escolha do que será lembrado: "os acontecimentos passados são escolhidos, aproximados e classificados conforme as necessidades ou regras" (HALBWACHS, 1990, p. 80). O esquecimento, portanto, opera junto com a memória.

Dito isso, percebe-se que os estudos da memória são bastante recorrentes na busca do entendimento de um determinado passado. Dentro da grande teia da memória, há várias subáreas como teorias da memória, o ato da rememoração de fatos históricos, a história oral ou a busca de algum arquivo ou documento para pesquisa. $O$ que se atenta é para a não sacralização do passado em meio a simples busca do que já se passou. O interessante, não apenas na ciência da História, mas também em outras áreas afins, é como esse passado e o resgate de determinado recorte pode nos ajudar a responder e a compreender diversas questões do presente.

Nos estudos da memória, "não se trata somente de não esquecer o passado, mas também de agir sobre o presente." (GAGNEBIN, 2006, p.55). Atenta-se também para 
o fato de que é uma área de estudo de extrema importância para tratar das "memórias subterrâneas" (POLLAK, 1989) dos esquecidos e dos silenciados.

A priori, são com esses esclarecimentos introdutórios que se compreende os estudos da teoria dos lugares de memória, do historiador Pierre Nora, que será brevemente abordada. Entre 1978 e 1981, Nora fez diversos seminários acerca de questões relacionadas à memória e à identidade, especificamente da França, na Écola des Hautes Études em Sciences Sociales, em Paris. Essas teses defendidas materializaram-se em tomos de um volume nomeado Les Lieux de Memóire, traduzido fielmente como lugares de memória. Nas palavras do próprio Pierre Nora,

\section{Os lugares de memória são, antes de tudo, restos. [...] Eles nascem e vivem do sen- timento de que não há me- mória espontânea, que é preciso criar arquivos, que é preciso manter aniversá- rios, organizar celebrações, pronunciar elegias fúnebres, notariar atas, porque essas operações não são naturais. [...] sem vigilância comemo- rativa, a história depressa os varreria (1993, p. 12-13).}

Nora aborda esses lugares não apenas como "espaços" (como frequentemente se entende pelo termo "lugar"), mas como uma série de expressões que representam a memória, a título de exemplo: objetos, arquivos, festas, comemorações, documentos, museus, uma obra de arquitetura ou monumentos. Eles possuem características "materiais, simbólicas e funcionais, simultaneamente, somente em graus diversos" (NORA, 1993, p. 21). Esses lugares de memória não o são por si, eles necessitam da imaginação e de diversos sentidos para tornar-se objetos ou expressões de memória: eles requerem uma "aura simbólica" para existirem como tal.

Um autor que aborda de forma clara a teoria de Pierre Nora e que nos auxilia em uma melhor compreensão é José Guilherme Abreu (2005), que relata em seu trabalho que "os lugares de memória são simultaneamente lugares in situ e lugares in visu, ou seja, que os lugares de memória constituem-se a um tempo enquanto coisa em-si e enquanto experiência para-nós: um feixe de realidade material e mental". (ABREU, 2005, p. 217, grifos do autor). Ele também trata da questão já citada da "aura simbólica", cujo fator imaginário só começa depois de uma certa vontade memorialista: um lugar de memória começa onde o mero registro acaba. (2005, p.219).

Com isso, percebe-se a força e a importância que a teoria de Pierre Nora possui para exemplificar e explicar determinados assuntos que abordam não só a área da História, mas também da Antropologia, Sociologia, Arqueologia e Artes Visuais, por exemplo. O alcance que a teoria propõe atinge um raio enorme de possibilidades de estudos e é bastante diverso. Com ela, será possível perceber uma outra faceta dos objetos - que aqui são, es- 
pecificamente, os monumentos de Rachel Whiteread - para compreender obras de arte pública através dos significados que os lugares de memória possuem.

Pode-se dizer que um monumento é uma herança, um patrimônio do passado. A cultura da construção de um monumento, desde a Antiguidade Clássica tende geralmente a ter dois eixos: o monumento como escultura funerária, no qual a morte é grande causadora para perpetuação da memória; e - monumento como arquitetura ou escultura (estátuas, bustos), que geralmente foram construídos para comemorar/homenagear algo/alguém.

Jacques Le Goff, em sua obra História e Memória, especificamente no capítulo intitulado Monumento/Documento, trata da discussão do conceito do monumento, que há séculos se alterou e se ampliou de acordo com as necessidades da história. Em um dos trechos, Le Goff retifica que o monumento tem como características o "ligar-se ao poder de perpetuação, voluntária ou involuntária, das sociedades históricas: é um legado à memória coletiva" (1996, p. 536). Portanto, vê-se que os monumentos têm relação direta com discussões que abordam o tempo, a memória e a sociedade. É importante relembrar que, como tudo o que é lembrado e que ativa a memória de algum feito histórico, a outra face do feito, não contada, fica, de certa forma, silenciada: o monumento que se constrói narra frequentemente apenas uma parte dessa história.
O monumento possui uma ligação direta com o espaço-tempo em que é produzido. Ademais do que já foi descrito, alguns monumentos, além de perpetuar a memória, servem também ao culto e à glorificação de divindades ou personalidades históricas. Geralmente, são erguidos para constituir um núcleo de grande prestígio da cidade: o espaço público, como a praça, o largo ou jardins públicos. Ele se situa, na maioria dos casos, no centro dessa zona aberta, e consequentemente seu posicionamento coloca-o em evidência.

De acordo com Abreu (2005), os monumentos podem ser classificados em tipologias, e estas são categorizadas a partir dos lugares de memória como metodologia. Ele divide em três tipos, sendo em ordem decrescente o nível de ativação da memória e de pertencimento que eles causam nos indivíduos.

O primeiro tipo é composto pelos Monumentos-Polo, que "forjam ícones de simbolização, a favor ou contra a sua elevação ou destruição, seu culto ou profanação"; o segundo tipo engloba os Monumentos-Sítio, que possuem uma "intenção narrativa/simbólica" e se subdividem em três classes: os monumentos, os memoriais e os anti-monumentos; e os últimos são os Não-Monumentos, que "não visam veicular nenhum tipo de narrativa. São, tão só, objetos estéticos" e abrem-se as portas apenas da intencionalidade poética e plástica. (ABREU, p. 221-222).

Portanto, partindo da premissa da teoria de Pierre Nora (1993) dos 
lugares de memória e das categorias dos monumentos estudada por José Guilherme Abreu (2005), serão abordadas duas obras monumentais da artista Rachel Whiteread, a começar pela primeira em ordem cronológica de construção, House.

\section{House e a materialização do espaço}

A obra intitulada House (1993/1994) foi concebida através da ordem de destruição das casas de um conjunto de habitações da era vitoriana, no East London, em Londres, na Inglaterra. A derrubada dessas casas foi realizada para a construção de um parque no local, e Whiteread concebeu seu trabalho quando a última casa do vilarejo vitoriano estava prestes a ser destruída.

House é o "molde" da última casa do conjunto que data do século XIX, mas não de sev exterior, familiar aos passantes, mas de seu interior. Não se trata apenas o molde do interior de uma casa vitoriana, Whiteread materializa a ausência de uma existência habitacional e de espaço. Nesse trabalho, o "oco" e o "vazio" tornaram-se matéria. House, além de tudo, foi uma escultura site-specific que não queria dar respostas, mas fazer ainda mais perguntas. E, claro, relembrar a memória daquele lugar.
Imagem 1 e 2- House (1993) com vista superior e respectivamente registrada pela parte de trás.
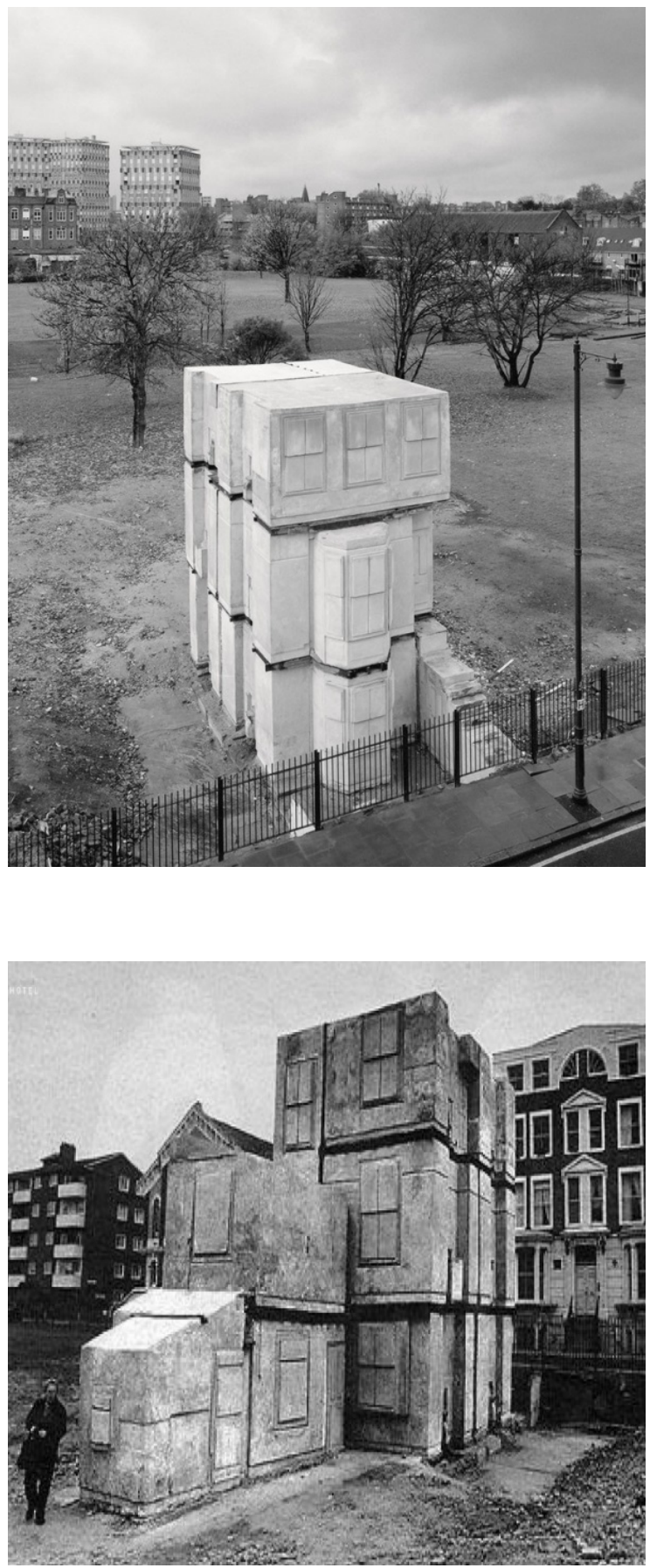

Fonte: Public Delivery. Disponível em: https:// publicdelivery.org/rachel-whitereadhouse/

Autor: John Davis.

Aqui, Rachel transforma a ausência do lugar em algo concreto. É uma escultura monumental que funciona como memorial: um mo- 
numento-sítio em que as vivências e habitações não existem mais, mas essa materialização funciona como metáfora para debatermos a memória e os aspectos sociais e culturais sobre processos de esquecimento e de gentrificação que ocorrem com muita frequência nas últimas décadas.

House surge como um megafone em forma de casa que grita por cada uma dessas pessoas: "eu vivi aqui". (SUBTIL, 2015, p.89) A obra foi construída exatamente onde existia a antiga casa, e Rachel possuiu uma extrema capacidade de criar uma "memória física", intrínseca à maneira de documentar o lugar. $O$ espaço (aquele não-arquitetônico) é universalmente imaginado como neutro, ou seja, como um espaço vazio:

Whiteread, no seu processo exploratório sobre o espaço, desenvolvido ao longo da sua vida e trabalho, não só mostra o vazio como ideia e construído arquitetônico como representa esse vazio que é cheio, um cheio cheio de histórias, memórias, emoções, um pedaço de mundo que fala às pessoas e dele mesmo. (SUBTIL, 2015, p.105)

A história da obra House, com sua aparência monumental e sua efemeridade, teve também imposição política. Sua obra foi dramática e rápida - para a comunidade artística, para a sociedade e também para os antigos habitantes - porém não deixou de causar impacto e carregar consigo uma variação de sentimentos, simbologias, metá- foras, reflexões e posicionamentos sociais e artísticos de Whiteread sobre a memória e o tempo. Raposo (2016) também remete ao valor dos destroços que a obra toma para si:

Este conceito também se relaciona com o valor da ruína, e como exemplo é possível citar a já referida House de Rachel Whiteread, onde a artista inglesa, ao reproduzir o vazio interior da casa através da matéria construída, remete para o valor dos seus destroços, enquanto um conjunto de objetos que revelam importância como testemunhas temporais, como objetos de valor formal e estético, além de se afirmarem, quase, como objetos políticos. (RAPOSO, 2016, p. 383)

É interessante notar também que vários críticos, artistas, curadores e principalmente arquitetos defendem muitas vezes a obra como "arquitetônica", e que existe um ciclo abstrato que transita entre escultura e arquitetura, e vice-versa. Portanto, a fronteira entre Arquitetura e Escultura é posta em causa: House é ou não Arquitetura? Para outros, a obra possui o status apenas de escultura: o espaço arquitetônico é habitável, tem uma função prática. Aqui, Whiteread não tem a intenção de firmar na obra a função de construção praticável. Rosalind Krauss (1984) define de forma clara a definição do que seria uma escultura nos pós-modernismo: "poderia dizer que a escultura deixou de ser algo positivo para se transformar na categoria resultante da soma da 
2 O texto "a escultura no campo ampliado", de Rosalind Krauss, publicado em 1979 é extremamente importante (inclusive nos dias atuais) para entender o conceito de escultura na pós-modernidade. Há uma busca nos processos artístico-históricos para desvendar as transformações dentro desse campo da arte, encontrando em Rodin (18401917) uma mudança significativa da perca do pedestal e da "monumentalidade" da obra escultórica. A autora também afirma que, após os anos 1960, a escultura estava na categoria de "terra-de-ninguém" (KRAUSS, 1984, p. 132), porém seu papel e significado de "marco" permanecem. não-paisagem com a não-arquitetura $2 "$." (KRAUSS, 1984, p. 133).

Há também um outro ponto interessante que a obra representa. Archer (2013, p. 208) lembra do problema dos sem-teto londrinos, e também da situação de famílias que precisam ser deslocadas/ sair do seu ambiente para "interesses maiores" do Estado. Ele aborda também as lembranças de outras residências há muito esquecidas e desabitadas.

A obra de Whiteread causou grande impacto entre duas situações: ganhou, por um lado, o Turner Prize de melhor jovem artista britânico no ano de 1993 e, no mesmo ano, ganhou também o prêmio da K Foundation para pior artista. Algumas personalidades, como o político Eric Flounders, foram grandes opositores e defensores da derrubada da obra, nomeando-a de junk e sugerindo que sua destruição seria para acabar com a afronta dos anarquistas à sua ideologia política. Houve grande debate e, ao final de pouco menos de quatro meses de sua duração, a obra foi derrubada em janeiro de 1994. A escultura em sua finitude não deixou de existir, uma vez que houve registros em jornais, fotografias e documentários. Apesar da sua efemeridade urbana, a obra não deixou de se tornar um monumento e uma representação, de fato, de um lugar de memória. Subtil dá um panorama do papel da obra de Whiteread:
Com isto, as Artes Visuais começam a empenhar-se numa estratégia de mudança do mundo, como o vemos, e do seu contexto social [...] Assim, um campo expandido da representação do espaço real surge fora das práticas tradicionais das artes, como afirma Delfim Sardo "a arquitetura trabalha sobre a realidade do espaço vivencial, e a arte trabalha sobre os mecanismos de representação da espacialidade". (2010, p. 28). (SUBTIL, 2015, p.96).

Toda a discussão sobre o esquecimento através da derrubada de lugares históricos, ou do processo de gentrificação das cidades tem ocorrido com grande força nos últimos anos. A obra de Rachel Whiteread é grande aliada para pensar a arte pública como resposta a esses problemas. Sua obra levanta questões como "o que a arte pública pode trazer/fazer para as pessoas?". Seu trabalho repercute de modo que a escultura nos espaços públicos possa fazer refletir sobre uma série de temáticas, desde a memória de um lugar até questões sociais e políticas. 


\section{"Jüdenplatz Holocaust Memorial" ou "The Nameless Library"}

Localizado no "Jüdenplatz" (praça dos judeus, na tradução literal), em Viena, o Memorial do Holocausto, também conhecido como "a Biblioteca Sem Nome" foi um monumento construído com a intenção de ser memorial, em homenagem aos mais de 65.000 judeus austríacos que morreram vítimas das atrocidades dos campos de concentração do nazifascismo. O monumento de Rachel foi o escolhido entre os dez que participaram de um concurso para artistas e arquitetos conceberem um projeto para tal homenagem, e, segundo a prefeitura de Viena, teriam algumas restrições que o projeto deveria atender, como, por exemplo, o fato do monumento não ser figurativo e de textos incluindo a lista de todos os campos de concentração nos quais os judeus austríacos foram mortos.

Descrevendo brevemente a obra, na sua base há descrições de textos que estão perto das portas. São textos em alemão, hebraico e inglês que denunciam o crime do Holocausto e o número das vítimas. No centro, há um desenho da estrela de Davi.
Imagem 3- Monumento do Holocausto, na Jüdenplatz, em Viena. Concebido em 2000.

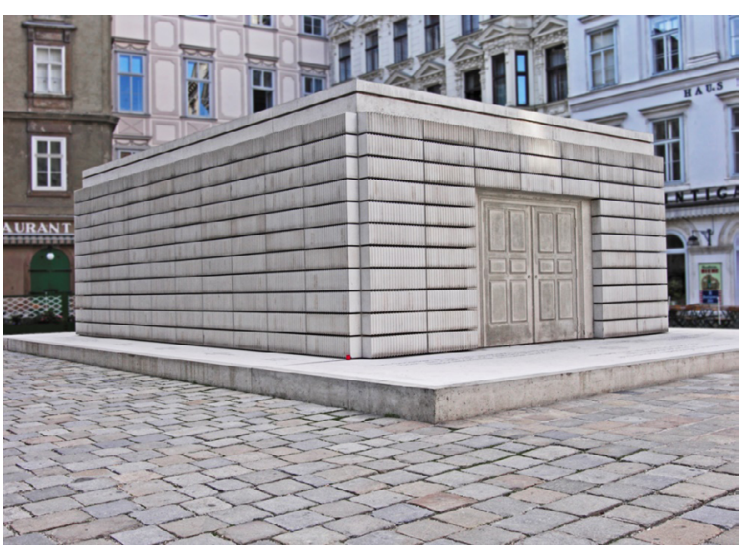

Fonte: Commons Wikimedia. Disponível em: https://commons.wikimedia.org/wiki/ File:Rachel whitereadwien holocaust mahnmal wien judenplatz.jpg. Autor: Hans Peter Schaefer.

As superfícies externas da obra (sua espécie de "parede") formam um tipo de estante de livros, cujas lombadas estão viradas para dentro do monumento. Estando seu conteúdo de forma a nunca serem vistos e lidos, sempre serão desconhecidos e nunca será revelado. Subtil faz um trabalho de metáfora interessante sobre a obra, na qual os livros podem estar relacionados "à burocracia e procedimentos Nazistas, à educação e conhecimento judeu, ou à lista interminável das vítimas". (2015, p.115). Suas portas não possuem maçanetas, portanto 0 lugar é impenetrável. Sua estrutura é feita basicamente de aço e concreto.

O memorial do holocausto também faz parte da categoria de arte site-specific e seria diferente se tivesse sido planejado em um outro local. Ele está conectado historicamente, artisticamente e socialmente com a Jüdenplatz. Há instituições na região da praça que guardam 
arquivos sobre o Holocausto, e uma estátua de um ativista da comunidade judaica está metros à frente do monumento. Um aspecto que está totalmente intrínseco ao memorial e que foi motivo de atraso de mais quatro anos na inauguração da obra foi uma descoberta nas escavações feitas pelos arqueólogos, bem abaixo de onde a obra está localizada.

Em 1995, nas escavações que precisariam ocorrer para a instalação do monumento, foi descoberta uma antiga Sinagoga do século XIII subterrada. Através dos vestígios que sobraram do edifício, também descobriram que a Sinagoga sofreu um incêndio em um ato nomeado Geserah Vienense: "devido ao massacre de centenas de judeus que, por se negarem a ser catolicamente batizados, foram queimados juntamente com o edifício" (SUBTIL, 2015, p.107). A sinagoga medieval, destruída no século $X V$, precisamente em 1421, marca 0 fim da primeira comunidade judaica em Viena.

Mesmo tendo vencido no concurso, a obra de Whiteread sofreu algumas críticas de muitos cidadãos, inclusive da comunidade judaica, que apontaram algumas inconveniências no projeto, como aspectos estéticos, políticos, religiosos e o fato de que a descoberta da antiga Sinagoga já seria suficientemente um memorial. Porém, a obra continuou sendo projetada e em 2000 foi inaugurada. Além de ser um memorial aos judeus dos campos de concentração, o monumento também funciona como mausoléu para as ruínas e em memória dos judeus mortos em 1421.
Esse monumento é um exemplo claro que transforma o "lugar de barbárie" em "lugar de cultura", conceitos tratados e discutidos criticamente por Georges Didi-Huberman (2017). Por mais doloroso que seja relembrar essas atrocidades, elas necessitam ser rememoradas de modo a pensarmos e analisarmos esses fatos de forma crítica. Também é importante a prática da memória para refletirmos os erros do passado. A obra de Rachel Whiteread produz esse trabalho com a memória, com o tempo e sua materialidade. Os vazios que ela "preenche" são cheios de histórias, sentimentos e lembranças. Monumentos-sítio que trazem questões importantes para refletirmos diante deles, e não apenas admirá-los.

A pedido da artista, o Memorial do Holocausto não recebeu revestimento anti-grafite. Ela disse que, se alguém borrifasse uma suástica na obra, podia-se tentar limpá-la, mas que algumas suásticas pintadas realmente fariam as pessoas pensarem sobre o que está acontecendo em sua sociedade. $O$ memorial foi inaugurado em outubro de 2000 e, mesmo sendo uma obra de arte, sua finalidade não era agradar esteticamente, mas que contrastasse com os edifícios barrocos e neoclássicos do redor com sua estrutura crua, pretendendo a reflexão da tragédia e da brutalidade dos fatos ocorridos. 


\section{Considerações finais}

Como visto, analisar os monumentos no espaço público através da teoria dos lugares de memória traz um outro reflexo da obra de arte contemporânea. Com o auxílio dessa teoria sobre a memória, os monumentos podem funcionar como "porta de entrada" para uma realidade bem mais complexa e ampla. Sabe-se que a investigação da arte pós-moderna, aqui em questão as obras de arte pública, consiste em estudos sobre as mais variadas esferas de assuntos, e a abordagem da memória é um deles. Como diz Pierre Nora em seu trabalho já citado: "os lugares de memória só vivem de sua aptidão para a metamorfose, no incessante ressaltar de seus significados e no silvado imprevisível de suas ramificações" (NORA, 1993, p.22).

Para relacionarmos o monumento público com a teoria dos lugares de memória, é interessante notar que há alguns pontos a serem considerados e debatidos. Abreu (2005) desenvolve três deles, como considerar a obra de arte pública de acordo com o seu lugar e contexto: o espaço, a sociedade nele inserida, as obras nele construídas. Tudo isso afeta e participa da relação do monumento como espaço de memória. Outro ponto que não se descarta é integrar a obra de arte no contexto da história da cidade e de seus acontecimentos/ desenvolvimentos/esquecimentos. Há também de se integrar o monumento na sua dimensão ética, contando com as participações e as tensões dos indivíduos.
Nota-se que a junção desses três pontos é imprescindível para a noção dos estudos das obras de arte no espaço público como lugares da história e da memória. A obras de Whiteread são essa espécie de condensação entre história, cultura e objeto de arte, criando vários dualismos e analogias que servem para refletir, como o limite entre escultura e arquitetura, público e pessoal, espaço externo e espaço interno, vazio e preenchido, passado e presente.

Para concluir, há um conceito de Platão que Subtil (2015) utiliza para exemplificar a obra de Rachel Whiteread e que traz uma compreensão interessante e valiosa acerca do espaço vazio que é materializado e preenchido:

O conceito que nos vai ajudar nesta análise, é khôra ou chora, conceito de Platão. Chora é definido por Platão como um espaço ou sítio localizado num limbo entre o inteligível e o sensível. Entendamos por inteligível, o que decorre da razão e do mundo das ideias, e por sensível, o mundo material. [...] chora é algo que não pode ser representado. Chora não pode ser representado, exceto no seu modo negativo. Não é nada sagrado ou teológico é um espaço. É um espaço que não pode ser representado, por isso é um desafio a qualquer coisa sólida, à arquitetura como algo construído. (SUBTIL, 2015, p.119, grifos meus). 
Portanto, os monumentos de Whiteread são uma forma de negativo construído, esse lugar que aparentemente não existe, mas que sua materialidade é possível. Sua potência em tornar física a ausência das coisas e a memória dos espaços é uma característica que transforma suas esculturas de simples concreto e aço em monumentos artísticos que narram histórias que poderiam ser esquecidas ou não ter evidência. Rachel Whiteread desempenha um papel, como chamaria Didi-Huberman (2017), de saber olhar as coisas de um ponto de vista arqueológico, comparando o que vemos no presente, o que sobreviveu, com o que sabemos ter desaparecido. Fica então sua obra como prova do olhar de um arqueólogo, e mesmo a obra House, destruída em 1994, não tem sua potência diminuída: o lugar, que agora permanece vazio, possuía um monumento que, justamente, criticava esse processo de simples destruição, apagamento e esquecimento. São monumentos-sítio, que também são história, arte, cultura e memória. 


\section{Referências}

ABREU, José Guilherme. Arte pública e lugares de memória. Revista da Faculdadede Letras, Ciências e Técnicas do Património, Porto, Portugal. I Série vol. IV, p. 215-2342005.

ARCHER, Michael. Arte contemporânea: uma história concisa. São Paulo: Martins Fontes 2013.

DIDI-HUBERMAN, Georges. Cascas. São Paulo: Editora 34, 2017.

GAGNEBIN, Jeanne Marie. Lembrar escrever esquecer. São Paulo: Editora 34, 2006.

HALBWACHS, Maurice. A memória coletiva. São Paulo: Editora Revista dos Tribunais, 1990.

KRAUSS, Rosalind. A escultura no campo ampliado. Revista do Curso de Especialização em História da Arte e Arquitetura no Brasil, PUC-Rio, n. 1, p. 129137. 1984.

KWON, Miwon. Um lugar após o outro: anotações sobre site-specificity. Revista Arte \& Ensaios n.17, EBA/UFRJ, p.167-187. 2009.

LE GOFF, Jacques. História e Memória. 4.ed. Campinas: Unicamp, 1996.

NORA, Pierre. Entre memória e história: a problemática dos lugares. São Paulo: Proj. história., v.10, 1993

POLLAK, Michael. Memória, esquecimento, silêncio. Rio de Janeiro: Revista Estudos Históricos, vol. 2, n. 3, p 3-15, 1989.

RAPOSO, Gabriela Maria Malheiros. O Espaço como matéria comum entre a Arquitetura e a Arte Contemporânea: contaminações entre as duas disciplinas. 2016 . Tese (Doutorado em Arquitetura). Departamento de Arquitetura . Universidade de Coimbra, Portugal. 2016.

SUBTIL, Ana Catarina Bispo. Os monólitos de Rachel Whiteread. Dissertação (Mestrado em Arquitetura), Departamento de Arquitetura. Universidade de Coimbra, Portugal, 2015.

Recebido em: $28 / \mathrm{set} / 2020$

Aceito em: 28/nov/2020 